\title{
Leveraging the Software Ecosystem Towards a Business Model Framework for Marketplaces
}

\author{
Tobias Weiblen, Andrea Giessmann, Amir Bonakdar and Uli Eisert \\ SAP Research, CEC St. Gallen, Blumenbergplatz 9, 9000 St. Gallen, Switzerland \\ \{firstname.lastname\}@sap.com
}

Keywords: Business Model, Marketplace, Software Industry, Software Ecosystems, e-Commerce.

\begin{abstract}
Software platforms in the form of marketplaces like Salesforce.com`s AppExchange, Netsuite`s SuiteApp or SAP`s Commercial Platform are changing the way how software and services are distributed, consumed, and priced. Technical innovations in the underlying platforms receive high attention, while innovative business models that build on and commercialize a flourishing ecosystem are neglected. In this paper we investigate the question which marketplace business model options are available to software platform owners that want to commercialize their ecosystem's products and services. We present a framework of ten possible models that is derived from both theory and practice. The options are clustered by the required level of product/service standardization to guide the choice of business model. The framework may serve decision makers as a starting point for their business model innovation plans.
\end{abstract}

\section{MOTIVATION}

Successful business models today are often multisided in nature. That is, a platform owner links markets from different sides of its network and thus can realize revenue streams on both sides (Eisenmann et al., 2006). Such business models are based on network effects: they not only require a customer base on one side of the platform but also depend on partners to cover the supply side. The more partners and customers participate, the higher the platform's overall attractiveness and thus the platform provider's chance of success (Katz and Shapiro, 1985; Katz and Shapiro, 1994; Parker and Van Alstyne, 2005).

Large software companies typically not only have a vast customer base using their products but are also surrounded by "ecosystems" of partners, who complement their offerings through software extensions or services (Bosch, 2009; van den Berk et al., 2010). It is hence no surprise that, in recent years, many software companies have successfully commercialized their software platforms in the form of marketplaces on which partner supply and customer demand are matched. Prominent examples include Salesforce.com's AppExchange, Apple's AppStore, Google's Android Market, and SAP's SAP Store. Typically, the platform owner receives a revenue share (e.g., 30\%) from every purchase made in the marketplace.

This predominant marketplace business model in the software industry works well for standardized digital products that can be sold immediately, such as media or software. Yet, only a fraction of a typical ecosystem's offerings can be commercialized in this way, particularly considering B2B markets and enterprise software. Current marketplaces in the industry fail to accommodate ecosystem players who offer more complex products and services such as, for example, customer specific enhancements and integration work (Bosch, 2009) or consulting services (Cusumano, 2008). We aim at closing this gap by answering the question which marketplace business models are available to commercialize ecosystem offerings and which factors influence model choice for the platform provider.

As a first result of our ongoing research, we present a set of marketplace business models that can be used by platform owners of the software industry to commercialize a larger share of their ecosystem's offerings. We do so by combining previous work in the field of business models and marketplaces with insights gained during several focus group meetings and interviews concerned with the research topic of our paper. Our framework systematically presents marketplace business models conceivable in a software ecosystem context. We thereby contribute to a broader perspective on 
software industry marketplaces that might also serve as a role model for other platform-based industries.

\section{THEORETICAL FOUNDATIONS}

\subsection{Business Models}

Business model research is an increasingly important area, especially in e-business. As early as 1954, Peter F. Drucker posed the following key questions to analyze and design business models: "(1.) What is our business? (2.) Who is the customer? (3.) What is value to the customer? (4.) What will our business be? (5.) What should it be?" (Drucker, 1954). Further prior studies that have also noted the importance of actively analyzing and designing business models include Timmers (1998), Rappa (2004), Mahadevan (2000), Morris et al., (2005), Osterwalder et al., (2005), Chesbrough (2007), and Zott et al., (2011). Based on an analysis of definitions for business models in literature, the definition of (Timmers, 1998) was taken as a basis for the research presented in this paper. According to Timmers, a business model is:

- An architecture for the product, service and information flows, including a description of the various business actors and their roles; and

- A description of the potential benefits for the various business actors; and

- A description of the sources of revenues.

Besides the definition of business models, Pateli and Giaglis (2004) distinguish seven more areas of business model research. The research presented within the paper at hand focuses on the research field design methods and tools. Meaning "building methods and developing tools for designing business models" (Pateli and Giaglis, 2004, p. 309).

\subsection{E-Marketplaces}

An electronic marketplace is a platform where demand and supply for certain goods meet in order to: (1) offer products and services in a structured manner as well as to select and find required products and services, (2) to negotiate the price and conditions, (3) to set up a contract, and (4) to pay and deliver the offered products and services (Bakos, 1991; Malone et al., 1987a; Schmid et al., 2002). A typical market transaction within an electronic marketplace therefore contains four specific phases: (1) information, (2) negotiation and price setting, (3) contracting, and (4) settlement. This already indicates the three major roles and players that are active on a marketplace. First, the providers of the product and services; second, the consumers of products and services; and, finally, the marketplace operator, who provides the market infrastructure and may support and participate actively, also taking a share of the revenues generated on the marketplace (Schmid et al., 2002).

\section{METHODOLOGY}

Overall, our research follows the design science research (DSR) approach (Hevner et al., 2004; March and Smith, 1995; Peffers et al., 2007). Design science focuses on the development of effective solutions for practical and theoretical problems by creating and evaluating artifacts intended to solve identified organizational problems (Hevner et al., 2004). Effective solutions in DSR must meet two central requirements: first, they must address a relevant organizational problem and, second, they have to add value to the knowledge-base.

Pursuant to DSR, requirements for the research are derived from the environment in order to ensure practical relevance. According to Hevner et al., (2004, p.80), environment in the sense of DSR consists of people, organizations and technologies. The research outlined within the paper at hand was conducted in the context of SAP's Commercial Platform that enables service providers to develop, publish, sell, and deploy their services (Wenzel et al., 2012), see also (Beimborn et al., 2011; Faisst, 2011). "The knowledge base is composed of foundations and methodologies" and provides "the raw materials from and through which IS research is accomplished" (Hevner et al., 2004). The paper at hand contributes to the knowledge base by developing a framework for a systematic and structured business model design in a software ecosystem context.

The design cycle is at the heart of the research. The iteration between the two core activities of designing and evaluating our framework allowed us to repeatedly validate and improve the artifact until a satisfactory design was achieved. Focus group discussions have been conducted to evaluate the developed framework. Focus groups are a special type of interviews involving a small group of interviewees at the same time (Morgan, 1998). The advantage of a focus group as compared to traditional interviews is the exchange of ideas and 
points of view among several participants. It allows expanding questions and addressing further aspects.

The framework has been evaluated against the real world by its reapplication in the context of SAP`s Commercial Platform. Since the evaluation is closely related with the designed artifact, these two main activities in DSR are presented together in the following chapter.

\section{MARKETPLACE BUSINESS MODELS}

\subsection{Decisive Parameters for Business Model Design}

In their groundbreaking work, Malone et al., (1987) analyze the influence of information technology on the coordination of economic activities. In summary, they predict that electronic markets will be increasingly preferred over hierarchical forms of coordination (such as stable supplier-buyer relationships) due to reduced search and coordination costs. They also identify two often interlinked product attributes to be the decisive parameters for the choice of organizational form: low asset specificity and low complexity of the product description favor electronic markets. Their predictions have been confirmed in a number of later studies (Daniel and Klimis, 1999) and also reflect in our observation that software company marketplaces today mainly sell standardized digital products. Less standardized products or services, consequently, might need different business models to be successfully commercialized.

Apart from the degree of product or service standardization, a multitude of aspects can play a role in designing marketplace business models. Transaction phases supported by the marketplace, for example, differentiate different models (Schmid et al., 2002) and depend on a range of institutional aspects (Reimers, 1996). In our context of software ecosystems, Cusumano (2008) mentions the trend of software companies moving towards service business and thus into previously partner-owned territory. This trend might also influence marketplace design on a more strategic level. In the following, we will come back to these aspects where they play an important role to motivate a specific business model.

\subsection{Overall Framework}

Within the scope of our research question, which is to identify marketplace business models that can be used to commercialize software ecosystem offerings, we identify ten overall possibilities. Each model is applicable in different contexts, yet the degree of product or service standardization is the most prominent driver that determines applicability. We hence use this parameter to cluster our framework of marketplace business models into three groups:

(1) Models for Standardized products/services, in which the marketplace serves as the primary channel for transactions and covers most of the transaction phases.

(2) Models for Configurable products/services, in which marketplace support is limited to a mediating and facilitating function, matching supply and demand.

(3) Models for Customer specific products/services, in which the platform owner's marketplace serves as a supportive channel only, guiding the customer to appropriate offerings outside the marketplace.

Figure 1 illustrates our framework. In the following sections, we describe the business models in each of the three groups and elaborate on them in more detail.

\subsection{Business Models}

\subsubsection{Primary Channel Models}

For products and services that are highly standardized, we identify four different models in which the transaction phases of the buying process are fully handled by the marketplace.

Restricted Model: Marketplace operators following the restricted model typically regulate market entry of product and service providers by offering unique services without substitutes or competing services. Consequently, a provider - once accepted - serves the whole market in its category.

Collaborating exclusively with only one provider per category is especially advantageous in highly price-oriented industries. On the one hand, the marketplace operator can avoid higher costs through more complex processes (Oppewal and Koelemeijer, 2005). On the other hand, the provider is able to realize economies of scale by serving a product or service category exclusively. An example for the restricted model is the cooperation of Ryanair and Hertz. Ryanair collaborates solely with Hertz to offer exclusive car rental rates to passengers during flight booking. 


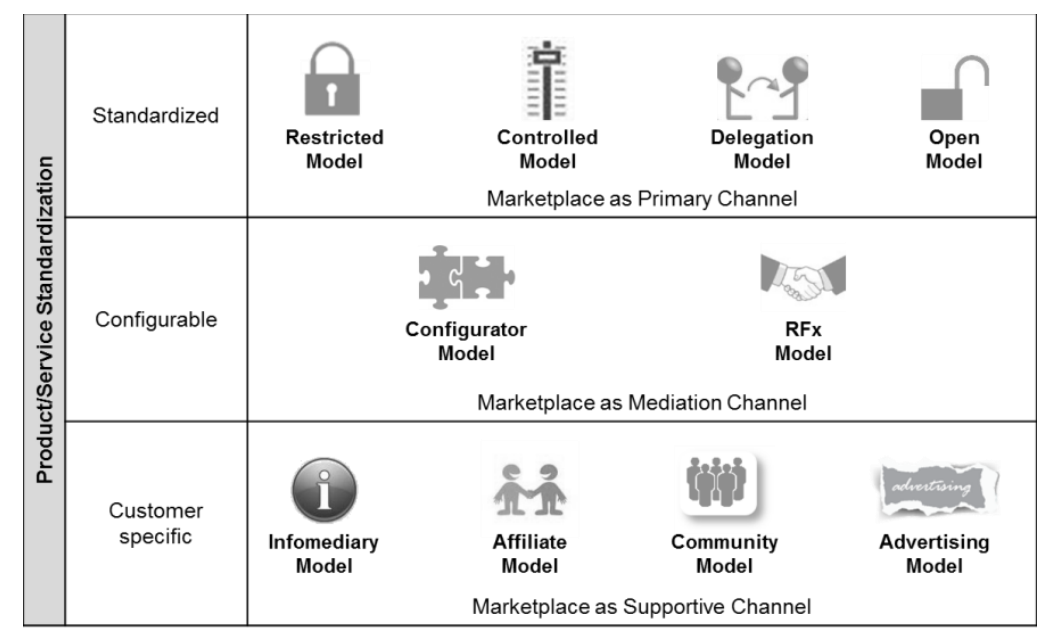

Figure 1: Framework of Business Models.

Controlled Model: In the controlled model market entry is also regulated by the marketplace operator. However, unlike in the restricted model, the controlled model allows for competing services, which puts more pressure on the service providers to differentiate. The controlled model is favorable in particular for companies with strong brands and/or a large customer base, which attract a large number of partners who try to skim market shares. Apple's App Store is a prominent example for the controlled model.

Delegation Model: Marketplace operators that follow the delegation model assign each service category to a selected partner. These partners act as category managers, very similar to the stationary retail industry. There, category managers "are responsible for integrating procurement, pricing, and merchandising of all brands in a category and jointly developing and implementing category-based plans with manufacturers to enhance the outcomes of both parties" (Basuroy et al., 2001).

The category manager has specialized knowledge and resources in his specific domain and receives a revenue share from the marketplace operator. Through using a category master, the operator can improve overall performance by providing the right mix of offerings in areas where his own expertise does not suffice to select partners.

Open Model: The open model follows a polypolistic approach by involving a large number of service providers who serve a large number of customers. Market entry is solely regulated by certain rules and guidelines that, once fulfilled by a service provider, lead to its listing on the marketplace. There is no control over the price and often providers are rated by customers. Open model marketplaces can, for example, be found in automated reservation systems like hotel.com or cheapflights.com for services and at ebay.com for products.

\subsubsection{Mediation Channel Models}

For products or services that are not standardized but can be described along a set of parameters, we identify two different models in which the marketplace takes over the role of a mediator that supports the negotiation process between customer and provider.

Configurator Model: The configurator model electronically supports negotiations with a single provider. Customers first select the provider, whose generic offerings are listed in a certain category, and then specify their wishes by means of supplierprovided parameters. The provider typically replies with a price quote and the offer to purchase "as specified".

In sophisticated configurator scenarios, quote and contract creation is automatized. Examples are car configurators or configurable PCs and laptops on dell.com. In other situations, the configurator can take more the form of a questionnaire to produce "qualified leads" which are then followed up by the provider individually and even outside the marketplace. Consequently, revenue schemes in the marketplace-supplier relationship can take the form of listing fees, revenue shares, or "per lead" payments. In the context of increasing productization of services (Cusumano, 2008), configurators are a promising means of productizing the aspect of complex service sales.

RFx Model: In contrast to the configurator model, which is applicable in case of a low number 
of providers in a certain category of the marketplace, the RFx model gives the customer a means of negotiating with many suppliers at the same time. The marketplace operator determines parameters that customers use to specify their wishes. In return, they receive quotes from multiple providers who promise to deliver the requested product or service. This scenario is aptly described as "reverse market" (Daniel and Klimis, 1999).

The model gives more power to the demand side and can be applied in highly competitive fields or when the marketplace owner has low strategic interests in the partnerships with product and service providers. Real-world examples include comparison sites for insurance contracts (e.g., insurancefinder.com) or tradesmen services (e.g., myhammer.com).

\subsubsection{Supportive Channel Models}

Products or services that are customer specific are, by our observations, rarely commercialized in today's platform provider marketplaces. Yet, they complement more standardized offerings and can benefit the entire marketplace by increasing completeness. Based on (Rappa, 2004), we identify four models for their commercialization.

Infomediary Model: In the infomediary (information intermediary) model, the marketplace operator plays a vital role in increasing market transparency (Rappa, 2004). A list of suppliers and their capabilities for a certain area is provided. The operator decides about the partners to be listed and might simply link to their websites for more information.

In this model, information and transparency are the main goal and we feel it is particularly suited for nascent markets that emerge, for example, around a new line of software products. Consequently, the software company operating the market place is interested in promoting its partners to increase own sales and does not charge a listing fee. Instead, it helps new partners gain traction in the market, utilizing its brand name to promote their offerings, (cp. Chu et al., 2005). An example is SAP's EcoHub (ecohub.sap.com) that lists, but does not sell, partner-provided services and solutions that are often customer specific.

Affiliate Model: The affiliate model focuses more on the monetization aspect of the partner listing - typical models are commissions or pay-perclick fees (Rappa, 2004). The marketplace operator still keeps control of which partner is listed but rather due to strategic and profit considerations - for example, to sell exclusive listings in some areas.

As in the other supportive models, the customer has "to contact those who made [the product or service] for further bilateral negotiations" (Reimers, 1996, p. 76). Emagister.com is an example for a company running the affiliate model. The site lists more than one million training courses in twelve countries but refers visitors to the respective course provider to place a detailed inquiry.

Community Model: Communities have a long tradition in the software industry. Most vendors today provide user and developer communities in which users support each other or propose new features (e.g., Microsoft's MSDN community MSDN.com). In those knowledge networks, experiences and expertise are shared among professionals (Rappa, 2004).

With regard to very specialized or niche markets, a promising option for marketplace operators is to use a community model to populate the marketplace with providers. An existing expert community works together to identify and rate niche players and their offerings to provide the best possible choice to other marketplace visitors. A similar approach is, for example, applied by Mapquest to populate maps with information on local businesses through open.mapquest.com.

Advertising Model: Populating the marketplace in form of the advertising model, the main focus of the provider shifts towards commercializing the traffic volume and the context provided by other marketplace entries (cp. Rappa, 2004). It is hence a model suitable for saturated markets with a high degree of competition. Potential providers pay to be listed in a certain marketplace category. As strategic considerations on the side of the platform provider are absent, any provider willing to pay and meeting few criteria can be listed.

Ebay.com, for example, even outsources the ad sales task to Google AdWords and provides their "sponsored links" in the context of its catalogue.

\section{CONCLUSIONS}

In our paper, we have looked at marketplace business models for software companies beyond the prevalent "standard software" and " $30 \%$ revenue share" paradigms. The resulting framework shows ten models that we derived both from literature and real-world examples. As we show, the choice of model by the marketplace operator predominantly depends on the degree of standardization of the product or service, but also on a wide array of other 
context aspects that we carved out per model.

During the course of our research, we have evaluated the framework in the context of SAP's Commercial Platform, conducting five focus group workshops with representatives from the marketplace operator role. Further, we have conducted interviews with potential partners (9) and internal experts taking on the customer role (16), thus evaluating the framework through all of the three marketplace roles. At current state, seven out of the ten models were selected for future use by the experts. This demonstrates that, in practice, different business models are needed to commercialize different types of products or services. Our contribution hence broadens the view of software ecosystem-based marketplaces in theory and practice. The theoretical and practical contributions may serve decision makers as a starting point for their business model innovation plans.

Future research could assess the framework's applicability to other contexts of platform industries to arrive at a more generalizable and more systematic description of the marketplace business models. Based on these foundations, a process model for selecting the right model in a specific context could be developed. Such a process model e.g., a decision tree or software tool - would support less knowledgeable users in finding the right business model.

\section{REFERENCES}

Bakos, J. Y. (1991). A Strategic Analysis of Electronic Marketplaces. MIS Quarterly, 15(3), 295.

Basuroy, S., Mantrala, M. K., and Walters, R. G. (2001). The Impact of Category Management on Retailer Prices and Performance: Journal of Marketing, 65(October), 16-32.

Beimborn, D., Miletzki, T., and Wenzel, S. (2011). Platform as a Service. Wirtschaftsinformatik, (6), 371375.

Bosch, J. (2009). From software product lines to software ecosystems. Proceedings of the 13th International Software Product Line Conference (SPLC '09) (pp. 111-119). Pittsburgh, PA: Carnegie Mellon University.

Chesbrough, H. W. (2007). Business model innovation: it's not just about technology anymore. Strategy and Leadership, 35(6), 12-17.

Chu, W., Choi, B., and Song, M. R. (2005). The Role of On-line Retailer Brand and Infomediary Reputation in Increasing Consumer Purchase Intention. International Journal of Electronic Commerce, 9(3), 115-127.

Cleven, A., Gubler, P., and Hüner, K. M. (2009). Design Alternatives for the Evaluation of Design Science
Research Artifacts. Proceedings of the 4th International Conference on Design Science Research in Information Systems and Technology (DESRIST) ( $\mathrm{p}$. 19:1--19:8). Philadelphia, Pennsylvania: ACM.

Cusumano, M. A. (2008). The Changing Software Business: Moving from Products to Services. Computer, 41(1), 20-27.

Daniel, E., and Klimis, G. M. (1999). The Impact of Electronic Commerce on Market Structure: An Evaluation of the Electronic Market Hypothesis. European Management Journal, 17(3), 318-325.

Drucker, P. F. (1954). The Practice of Management. New York, USA: Harper and Row Publishers.

Eisenmann, T., Parker, G. G., and Van Alstyne, M. W. (2006). Strategies for Two-Sided Markets. Harvard Business Review, 84(10), 92-101.

Faisst, W. (2011). Die nächste Generation der Unternehmens-Software am Beispiel von SAP Business ByDesign. Wirtschaftsinformatik and Management (WuM), 04, 24-31.

Hevner, A. R., March, S. T., Park, J., and Ram, S. (2004). Design Science in Information Systems Research. MIS Quarterly, 28(1), 75-105.

Katz, M. L., and Shapiro, C. (1985). Network Externalities, Competition, and Compatibility. The American Economic Review, 75(3), 424-440.

Katz, M., and Shapiro, C. (1994). Systems Competition and Network Effects. The Journal of Economic Perspectives, 8(2), 93-115.

Mahadevan, B. (2000). Business models for Internet-based E-commerce: An anatomy. California Management Review, 42(4), 55 - 69.

Malone, T. W., Yates, J., and Benjamin, R. I. (1987). Electronic markets and electronic hierarchies. Communications of the ACM, 30(6), 484-497.

March, S. T., and Smith, G. F. (1995). Design and natural science research on information technology. Decision Support Systems, 15(4), 251-266.

Morgan, D. L. (1998). The Focus Group Guidebook (p. 120). Thousand Oaks, California: Sage Publications, Inc.

Morris, M., Schindehutte, M., and Allen, J. (2005). The entrepreneur's business model: toward a unified perspective. Journal of Business Research, 58(6), 726735.

Oppewal, H., and Koelemeijer, K. (2005). More choice is better: Effects of assortment size and composition on assortment evaluation. International Journal of Research in Marketing, 22(1), 45-60.

Osterwalder, A., Pigneur, Y., and Tucci, C. (2005). Clarifying business models: Origins, present, and future of the concept. Communications of the Association for Information Systems (CAIS), 16(1), 125.

Parker, G., and Van Alstyne, M. (2005). Two-Sided Network Effects: A Theory of Information Product Design. Management Science, 51(10), 1494-1504.

Pateli, A. G., and Giaglis, G. M. (2004). A research framework for analysing eBusiness models. European Journal of Information Systems, 13(4), 302-314. 
Peffers, K., Tuunanen, T., Rothenberger, M. A., and Chatterjee, S. (2007). A Design Science Research Methodology for Information Systems Research. Journal of Management Information Systems, 24(3), 45-77. M. E. Sharpe, Inc.

Rappa, M. (2004). The utility business model and the future of computing services. IBM Systems Journal, 43(1), 32-42.

Reimers, K. (1996). The non-market preconditions of electronic markets: implications for their evolution and applicability. European Journal of Information Systems, (5), 75-83.

Schmid, B. F., Stanoevska-Slabeva, K., Lechner, U., and Seufert, S. (2002). Elektronische Märkte. In R. Dubs, D. Euler, and J. Rüegg-Stürm (Eds.), Einführung in die Managementlehre (pp. 831-849). Bern, Switzerland: Haupt.

Timmers, P. (1998). Business Models for Electronic Markets. Electronic Markets, 8(2), 3-8.

Wenzel, S., Faisst, W., Burkard, C., and Buxmann, P. (2012). New Sales and Buying Models in the Internet: App Store Model for Enterprise Application Software. In D. C. Mattfeld and S. Robra-Bissantz (Eds.), Multikonferenz Wirtschaftsinformatik 2012 Tagungsband der MKWI 2012 (pp. 639-651). Braunschweig: GITO Verlag.

Zott, C., Amit, R., and Massa, L. (2011). The Business Model: Recent Developments and Future Research. Journal of Management, May(2), 181-199.

van den Berk, I., Jansen, S., and Luinenburg, L. (2010). Software Ecosystems: A Software Ecosystem Strategy Assessment Model. Proceedings of the Fourth European Conference on Software Architecture Companion Volume - ECSA '10 (p. 127). New York, New York, USA: ACM Press. 